Original Scientific Article

\title{
THE BIOPSY OF BOAR TESTES USING ULTRASONOGRAPHIC EXAMINATION
}

\author{
Laima Liepa, Zigmunds Bruveris, Mara Mangale, Ilmars Duritis, \\ Vita Antane, Alberts Auzans \\ Clinical Institute, Faculty of Veterinary Medicine, Latvia University of Agriculture
}

Received 10 October 2013; Received in revised form 21 November 2013; Accepted 9 December 2013

\begin{abstract}
The biopsy of live animal testes is an important clinical manipulation to control spermatogenesis and reproductive system pathologies. The aim was to develop a method of boar testes biopsy using a biopsy gun with ultrasound guidance and to investigate the influence of this procedure on the boar testes parenchyma and quality of ejaculate. The biopsy was carried out in six 8-month-old boars. Fourteen days prior to and 21 days after biopsy, the quality of ejaculate was examined (weight of ejaculate; concentration and motility of spermatozoa) with a seven-day intervals. Ultrasound images of the testes parenchyma were recorded three times: directly before and 15 minutes after the biopsy, then 21 days after the procedure. The testes biopsies of generally anesthetized boars were performed with the biopsy gun for needle biopsy with a $12 \mathrm{~cm}$ long, disposable 16-gauge needle $1.8 \mathrm{~mm}$ in diameter (Vitesse) through $1 \mathrm{~cm}$ skin incision in the depth of $1.2-1.6 \mathrm{~cm}$ of parenchyma. Fifteen minutes after the biopsy, macroscopic injures of the parenchyma of all the boar testes were not detected in the ultrasound image. Twenty one days after biopsy, the hyperechogenic line $0.1-0.2 \mathrm{~cm}$ in diameter was seen in the testes parenchyma of six boars in the depth of $1.2-1.6 \mathrm{~cm}$. The biopsy of boar testes did not influence the quality of boars ejaculate. The ultrasonographic examination of boar testicles before the biopsy reduced possibilities to traumatize large blood vessels of the testes. A perfect boar testicular biopsy was easy to perform using ultrasonographic examination in the pigsty conditions.
\end{abstract}

Key words: boar; testicular biopsy; ultrasonographic examination

\section{INTRODUCTION}

Testicular biopsy is one of the supplementary examinations performed in the course of andrological testing. In veterinary medicine this method is seldom used to investigate low-fertility or suspects for cancer in dogs, stallions, bulls and rams $(5,9,10,12)$. This method can be applied to many animal species. Testicular biopsy consists of the operative removal of a piece of tissue from the testis, so small as to have no deleterious effect on the gland, yet large enough to include a representative group of tubules. Several techniques to obtain a testicular biopsy specimen have been described:

Corresponding author: Prof. Laima Liepa, $\mathrm{PhD}$

E-mail address: Laima.Liepa@1lu.lv;

Present address: Clinical Institute, Faculty of Veterinary Medicine,

LUA, Helmana 8, Jelgava, Latvia, LV-3004;

tel: +371 63021972 / fax: +371 63027344

Copyright: (C) 2014 Liepa L. This is an open-access article published under the terms of the Creative Commons Attribution License which permits unrestricted use, distribution, and reproduction in any medium, provided the original author and source are credited.

Competing Interests: The authors have declared that no competing interests exist.

Available Online First: 16 December 2013

http://dx.doi.org/10.14432/j.macvetrev.2013.12.006 standard open surgical biopsy (or incisional biopsy), needle punch biopsy, biopsy gun needle biopsy and fine needle aspiration (FNA) (12). Open method involves the removal of a section from the testicular parenchyma through incisions made in the scrotum, tunica vaginalis (lamina parietalis et lamina visceralis), and tunica albuginea. Split needle biopsy is performed using a special instrument that is introduced through an incision made in the scrotum followed by puncturing of the tunica vaginalis against the tunica albuginea into the testicular parenchyma. Needle punch biopsy is performed in a manner similar to that of the split needle biopsy using a needle with a large caliber. The needle is introduced through a small incision in the scrotum toward the center of the testicle. Alternatively, a percutaneous puncture of the testis can be performed. In the testicular FNA, the testis is percutaneously punctured by using a small caliber needle. The incisional and the split needle biopsy methods provide satisfactory tissue for histologic examination or to measure testicular hormone concentrations. These methods are considered 
to be mildly (split needle) to moderately (open) invasive and traumatic $(8,12,13)$. The biopsy gun method is particulary described for testicular biopsy in humans. The use of biopsy gun for testicular biopsy in veterinary medicine was first reported by Hillman et al., 1994. The depth of the biopsy with the standard biopsy gun was $22 \mathrm{~mm}$. Testicular biopsy was performed in a total of 14 stallions and no histopathologic changes, no significant decrease in any of the semen quality parameters due to the biopsy procedure were identified (12). The most traumatic is incisional biopsy method. The experiment has been done with dogs: 75 mixed breed intact male dogs were biopsied by needle punch (Tru-cut needle) method $(n=36)$ and by incisional method $(\mathrm{n}=39)$. There has been a positive correlation $\left(r^{2}=0.93\right)$ between testicular circumference and occurrence of lesions. Incisional biopsies induced more gross lesions (33\%), and more histologic lesions (43\%), the lesions were of greater severity and incidence than those in Tru-cut biopsy specimens. It was concluded that incisional biopsy induced an increase in frequency and severity of lesions compared with Tru-cut biopsy of the canine testicle (9). A procedure for testicular biopsy was developed and tested in rams at 14, 18 and $22 \mathrm{wk}$ of age. The biopsy procedure produced a tissue sample with minimal cell-to-cell disruption and caused no detectable detriment to testicular development in rams. At least three biopsies from the same testis were obtained at 4-week intervals. These results demonstrate that repetitive testicular biopsy can be performed successfully in the ram during pubertal development. The biopsy procedure allows repeated sampling of the same animal and offers a reasonable alternative to castration (10). The incisional testis biopsy method of boars is described by Hall et al., 1984 (6), where a $1 \times 2 \times 2 \mathrm{~cm}$ piece of testicular parenchyma was removed for virus isolation. Hemostasis was achieved by suturing the incision: the skin was closed with continuous interlocking non-absorbing sutures. It is necessary to know boar testis anatomy for safe biopsy procedure, in order to foresee potential bleeding risk and hematoma formation. The boar testis is well vascularized. The a. testicularis enters in the testis from the extremitas capitata and ramifies in the tunica albuginea. The branches of testicular artery coming from the margo epididymalis provide a blood supply to the margo liber of boar testis. From the branch, which is supplying blood to the margo liber, rami testiculares mediales radiates to the medial region of testis, but rami testiculares laterales radiates in the lateral part of boar testis. The rami testiculares laterales branches in the tunica albuginea, in the lamina visceralis tunicae vaginalis and the parenchyma (1). In domestic and laboratory animals, accurate information regarding side effects of each type of biopsy in different species is scarce. Lesions such as sperm granulomas, spermatoceles, and neoplasia are easily visualized with B-mode ultrasound (13). The most common complications in stallions after testis biopsy procedure are hematomas occurring between the testicular tissue and the tunicae, or between the scrotum and tunicae. They usually result from vigorous manipulation with the testicle, such as excessive torsion or tension on the testicle or vasculature of the testicle. Hematomas resolved without adverse effects on stallion's fertility (5). Hemorrhage can be controlled with exerting gentle pressure on the tunicae with a sterile sponge for 1-2 minutes (4). Ultrasound method is described only for the measurement of length and width of the testes of anesthetized boars $(2,3)$, not for the examination of boar testes blood vessels or parenchyma. The aim of the experiment was to develop a method of boar testes biopsy using a biopsy gun with ultrasound guidance and to investigate the influence of this procedure on the boar testes parenchyma and breeding ability.

\section{MATERIALS AND METHODS}

The biopsy was carried out in six 8-month-old boars in the vivarium of the Faculty of Veterinary Medicine, Latvian University of Agriculture. All experimental procedures were performed in accordance with guidelines of the Council of the European Communities Directive of 24 November 1986 (86/609/EEC) and were approved by Ethics Counsil of Animal Protection at the Veterinary and Food Service, Riga, Latvia (Nr.22; 04.15.2010). The quality of boars' ejaculate was examined (weight of ejaculate, concentration, and motility spermatozoa). The semen was collected on the dummy using manual fixation of penis with a 7-day intervals 14 days prior to (3 times) the biopsy and 21 days after (3 times) the biopsy. Six ejaculates in total were collected from each boar during the experiment. Immediately after collection, the ejaculates were weighed, filtered(US BAGTM; Minitube, Germany) to remove gel and the sperm concentration in gel-free fraction was determined with photometer (SpermaCue; Minitube, Germany). The motility of spermatozoa was determined by taking a drop of 
semen on a warmed glass slide $\left(37^{\circ} \mathrm{C}\right)$ and covered with a cover slip. At least five fields of vision were looked through, and in each field, ten spermatozoa were evaluated at magnification of 100x, 200x and 400x under the light microscope. The same procedure was repeated four times in each ejaculate as a blind evaluation done by the same person. The proportion of progressive motility of spermatozoa was estimated by a ten-point score system. If all $(100 \%)$ spermatozoa were progressively motile, then 10 points were assigned, if $90 \%$ spermatozoa were progressive motile, then 9 points, and so on.

The general anaesthesia of boars was done with $7 \mathrm{ml}$ of $10 \%$ ketamine (Ketamin 10\%; Bremer Pharma GMBH, Germany) infusion intravenously in $v$. auricularis intermedia. Ultrasound images of the testes parenchyma were recorded three times: directly before the biopsy to exclude potential pathologies and to find the best place for puncture, 15 minutes after the procedure for detection of potential injures of tissue and hematomas, and 21 days after the biopsy for evaluation the aftereffects of the biopsy. An examination was performed with ultrasound equipment Philips HD11 using a linear probe $\mathrm{L} 12-3 \mathrm{MHz}$ in the middle region of the scrotum to detect the safest site of biopsy (without large blood vessels). Prior to the biopsy, the testis region was prepared for surgery with $70 \%$ ethanol, and $1 \mathrm{~cm}$ skin incision was made. A biopsy gun for needle biopsy was used with a $12 \mathrm{~cm}$ long, disposable 16-gauge needle $1.8 \mathrm{~mm}$ in diameter (Vitesse). The twelve tissue samples from both testes of six boars (1.2 to $1.6 \mathrm{~cm}$ in length and $0.1-0.2 \mathrm{~cm}$ in diameter) were fixed in $10 \%$ neutral buffered formalin for 48 hours at room temperature, then dehydrated in the tissue processor (TISSUE-TEK II), and embedded into paraffin blocks applying standardized tissue histological procedure, cut in $4 \mu \mathrm{m}$ thick sections and stained with haematoxylin-eosin and Masson's trichrome (7). The histological slides were processed using an optical microscope (Leica DM500B) with the program Image-Plus 6.1.

Two months after the biopsy, all experimental boars were castrated and histological slides of the testes parenchyma from the region of puncture were prepared.

The data of boars ejaculate quality were statistically analysed by SPSS 11.5. All parameters of ejaculates and sperm motility were checked for normality and expressed as means \pm SEM. Differences between times of boars ejaculate sampling were analyzed by a two-tailed paired Student's $t$-test. A significance level of $\mathrm{P}<0.05$ was accepted throughout the study.

\section{RESULTS}

The sonographic examination of boar testicles was performed before the biopsy, and no pathological abnormalities were found. The testicles of boars were of medium echogenicity with homogenous echotexture. The testicular border was characterized by a thin, smooth and hyperechoic line of the tunicae albuginea. On longitudinal view, the mediastinum of testis was visible as a central hyperechoic line, but on transversal view, the mediastinum appeared as a centrally located hyperechoic focus, $2.3-3.6 \mathrm{~cm}$ from the tunicae albuginea (Fig. 1A).
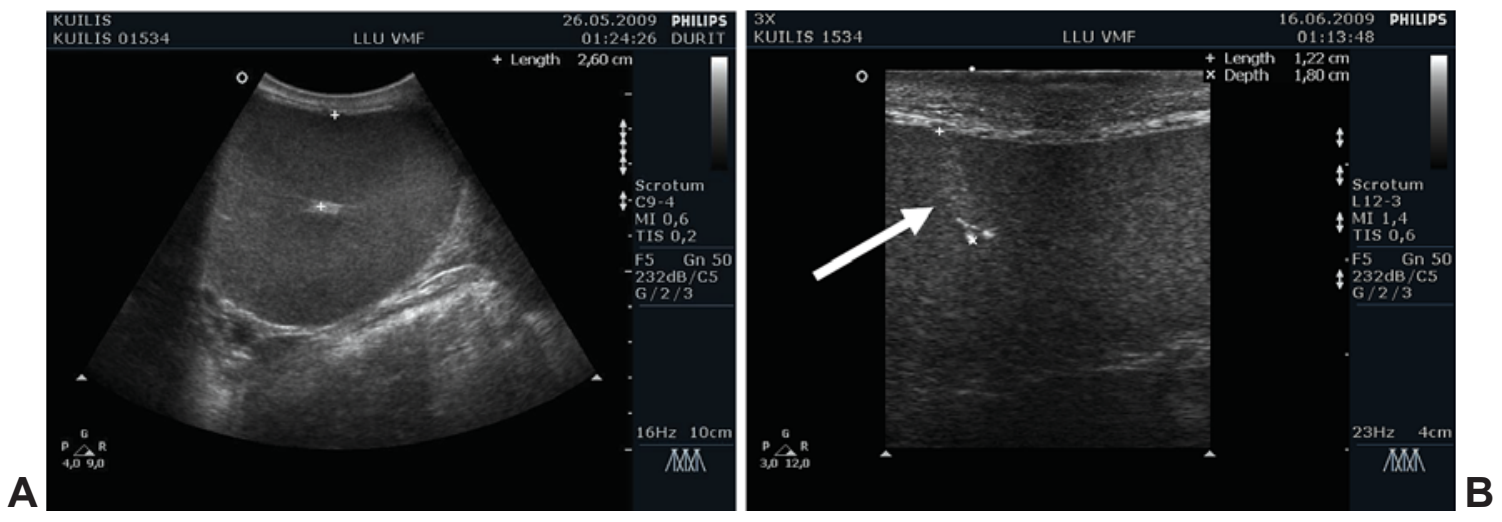

Figure 1. (A) The sonographic image of a transversal view of boar testis performed before the biopsy. The depth to the mediastinum was $2.6 \mathrm{~cm}$ (boar Nr. 1534). (B) Twenty one days after the biopsy the hyperechogenic line was visible in the depth of $1.22 \mathrm{~cm}$ (boar No.1534). 
Fifteen minutes after the biopsy, macroscopic injuries of the parenchyma and noticeable hematoma of all the boar testes were not detected in the USG image (Fig. 2A).
In the tissue of testis, between the convoluted seminiferous tubules there was a well developed stroma consisting of interstitial connective tissue composed of fibrocytes, fibroblasts, collagen fibers,
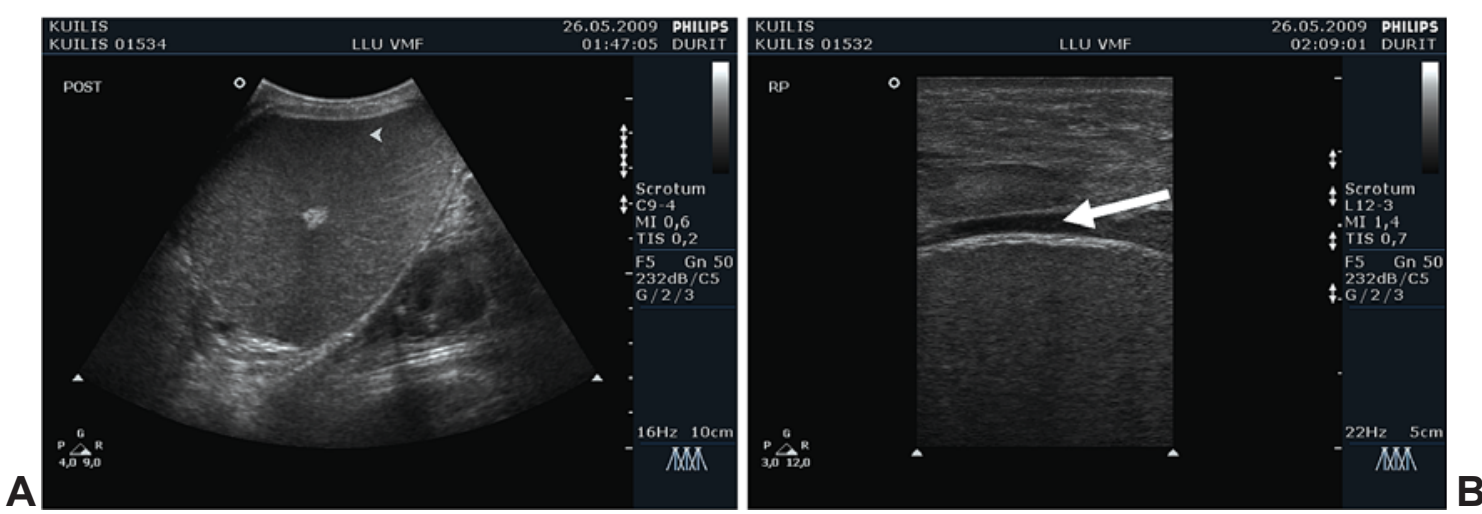

Figure 2. Fifteen minutes after the biopsy, (A) in the boar Nr.1534 no significant injures of the parenchyma were detected in the ultrasound image. (B) In the boar Nr. 1532 a hematoma was observed in the vaginal cavity.

Two boars out of six had an extended (1-2mm) cavum vaginale (space between lamina visceralis et lamina parietalis, tunica vaginalis). Hematoma could be formed due to traumatizing of blood vessels at the time of the biopsy procedure (Fig. 2B).

Twenty one days after the biopsy, there were no more signs of hematoma, the hyperechogenic line $0.1-0.2 \mathrm{~cm}$ in diameter was seen in the testes parenchyma in the depth of $1.2-1.6 \mathrm{~cm}$ (Fig. 1B).

The first histological examination of the experimental boar testes parenchyma was performed using tissues from the testes biopsy. The acquired testicular tissues were of good quality, without blood contamination and sufficient enough for histological examination.

In the histological slides of biopsy material, typical structures of the boar testis were observed (Fig. 3A). blood vessels, lymphatic vessels, free mononuclear cells, and a lot of Leydig cells. In the seminiferous tubules, the process of spermatogenesis was well traced. The remains of traumatized seminiferous tubules were seen in the center of the incision.

The histological examination at the place of the testes puncture presented a normal process of granular tissue development with a small increase in the number of mononuclear cells. No signs of hematoma were detected either below the tunica albuginea or in the stroma of the testis and the cavum vaginale. A normal process of spermatogenesis in the convoluted seminiferous tubules was observed around the place of puncture. In slides prepared from the tissue samples taken to the left of the puncture place, normal structure of the parenchyma, stroma and blood vessels of the boar testis were distinguished typical of the species (Fig. 3B).
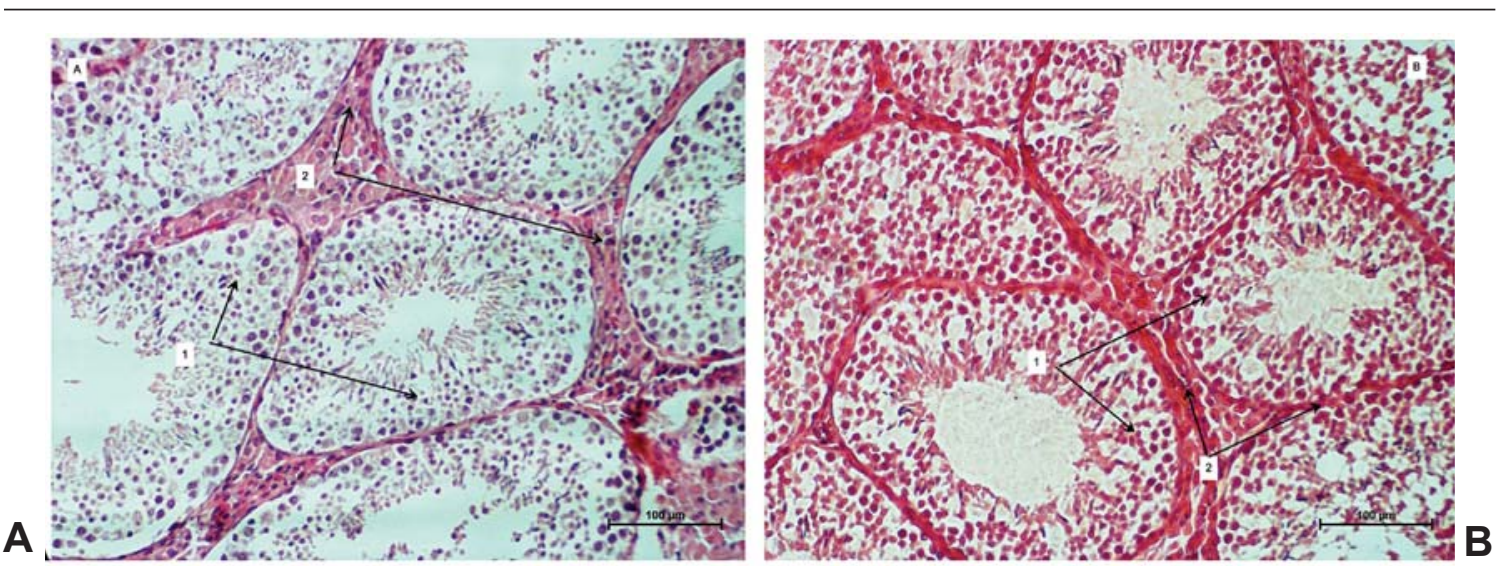

Figure 3. Convulated seminiferous tubules (1) and intertubular tissue (2) were seen in the histological slide of the boar testis biopsy (A). Histological sample of the boar testis taken two months after the biopsy (B). (Hematoxylin-eosin staining, $200 \mathrm{x})$. 
The biopsy of boar testis did not influence the quality of ejaculate of boars. There were insignificant differences $(p>0.05)$ between the mean weight of ejaculate, concentration and motility of spermatozoa 14 days prior to the biopsy and 21 days after the biopsy (Fig. 4, 5, 6). The third time in all these figures represents the quality of ejaculate few hours before the biopsy procedure.

The increase of the weight of boar ejaculate was insignificant $(p>0.05)$ : at the beginning of the study it was $166 \pm 8.5 \mathrm{~g}$ and at the end $-275 \pm 77.1 \mathrm{~g}$, with more intensive rise after the fourth time of the semen quality assessment (Fig. 4).

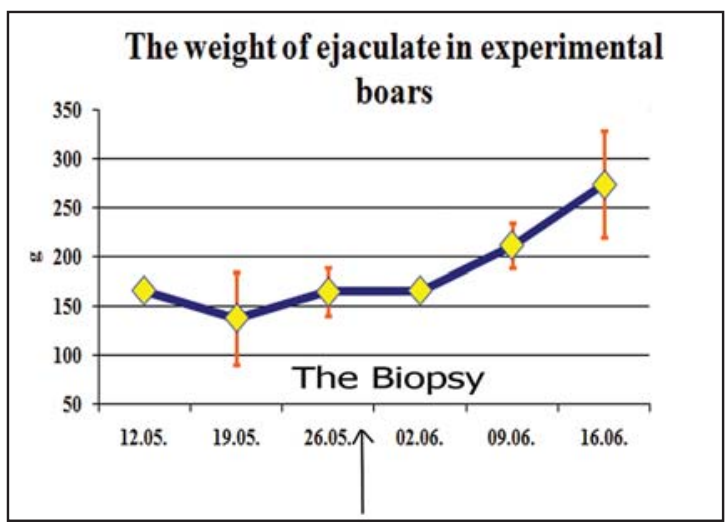

Figure 4. The weight of ejaculate of six experimental boars during the experimental period (mean \pm SEM). The third evaluation (26.05.) was 1-2 hours before the biopsy procedure (the blue arrow).

The mean concentration of spermatozoa in the boar ejaculate was various with statistically insignificant ( $p>0.05$ ) changes; at the beginning of the experiment it was $388 \pm 24 \times 10^{6}$ cells $/ \mathrm{ml}$, but at the end $-430 \pm 29 \times 10^{6}$ cells/ml (Fig. 5).

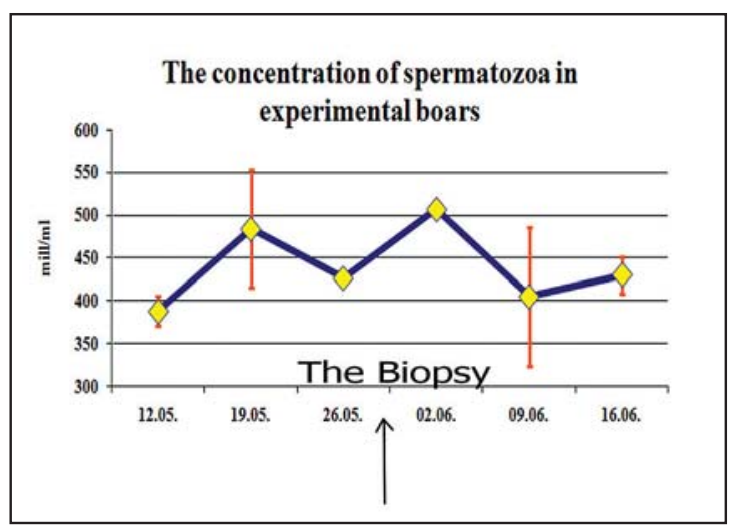

Figure 5. The concentration of spermatozoa in the ejaculate of six experimental boars during the experimental period (mean \pm SEM). The third evaluation (26.05.) was 1-2 hours before the biopsy procedure (the blue arrow).
The mean motility parameters of spermatozoa during the experiment were similar around 7.5 points, with an insignificant $(\mathrm{p}>0.05)$ increase at the end of the experiment $8.0 \pm 0.71$ points (Fig. 6).

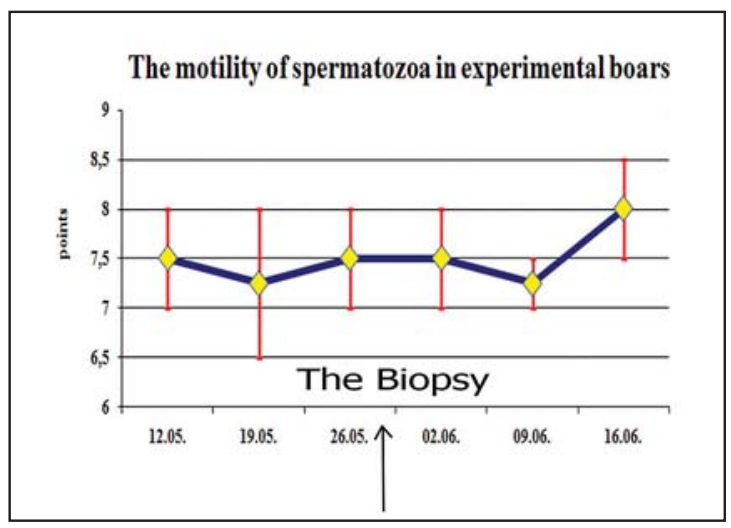

Figure 6. The motility of spermatozoa of six experimental boars during the experimental period (mean $\pm \mathrm{SEM}$ ). The third evaluation (26.05.) was 1-2 hours before the biopsy procedure (the blue arrow).

\section{DISCUSSION}

Results of our investigation demonstrate that the boar testes ultrasound guided biopsy (under anesthesia with Ketamine) with Vitesse biopsy gun did not reduce quality of ejaculate (Fig. 4, 5, $6)$. These results correspond with other studies $(11,12,13)$. The small testis injury from the needle of the biopsy gun in the depth of $1.2-1.6 \mathrm{~cm}$ did not influence a normal process of spermatogenesis in the rest of testis. No detrimental effect to testicular development in the experimental boars was observed. The insignificant $(p>0.05)$ increase in the volume of boar ejaculate could be associated with the growing process of 8-month-old boars. In the obtained samples of testes biopsies, the number of normal convoluted seminiferous tubules and interstitial tissues was sufficient to characterize the process of spermatogenesis and analyze the interstitial tissues.

The most traumatic is the incisional biopsy method (9). Incisional biopsies induce more gross lesions and more histological lesions than the needle puncture in diameter of $1.8 \mathrm{~mm}$ using biopsy gun method. Using the biopsy gun, there are also possibilities to change the depth of puncture very precisely. Using the needle punch method, one can use a needle with a larger diameter and the puncture is done more slowly with the pressure of the hand. Needle punch biopsy presents potential risk for traumatic injuries to the testis (8). The FNA method 
gives more split tissue material, and sometimes the procedure needs to be repeated in order to get testicular material sufficient enough without blood for histological examination. The lack of a detailed explanation about how to perform and interpret the results of testicular FNA in animals might be the reason as to why this technique has still not been used as widely as that in men (8). It means, the biopsy gun method is the easiest applicable, it provides satisfactory tissue for histologic examination and is the least traumatic in comparison with the other testicular biopsy methods, especially when combined with ultrasound monitoring.

Occurrance of hematoma between the tunicae (in the cavum vaginale) is the most often detected complication after the biopsy of animal testicles $(4,5)$ which disappears without visible pathologies. Considering the specific vascularization of boar testes (1), the ultrasound examination of the testis margo liber before the biopsy procedure helps avoid traumatization of larger blood vessels in the place of puncture, thereby reducing the risk of hematoma forming. In our experiment only two boars had negligible hematoma recognized in ultrasound examination 15 minutes after the puncture; however that did not reduce the reproductive performance of animals. Two months after the biopsy all experimental boars were castrated, and there was no adhesion and testes were freely situated in the vaginal cavity.

Theoretically, pathologies could rise in cases of doing unsterile procedures: making mistakes when preparing the place of puncture, getting manure on the surface at the time of cutting the skin, using unsterile needles or the boar lying down in manure after procedure. In such situations environmental pathogens could provoke an inflammation process in testicles - orchitis with succeeding abscess formation. (11)

In conclusion, the biopsy of boar testicles with Vitesse biopsy gun using ultrasonographic examination did not influence the quality of ejaculate of boars - the weight of ejaculate, the concentration and motility of spermatozoa were similar before and after the biopsy procedure without significant changes during 21 days period. The ultrasound guidance of boar testicles before the biopsy reduced possibilities to traumatize the large blood vessels of the testis. A perfect biopsy of the boar testicles under ultrasound guidance was easy and safe to perform in pigsty conditions.

\section{ACKNOWLEDGMENTS}

This study was supported by a grant from the Scientific Council of the Ministry of Agriculture of Latvia (project No. 09.1528).

\section{REFERENCES}

1. Böttcher, M., Lange, W. (1987). Untersuchen am arteriellen Gefäßsystem des Eberhodens. Archiv für Experimentelle Veterinärmedizin, Leipzig. 41, 58-64.

2. Cartee, R.E., Powe, T.A., Gray, B.W., Hudson, R.S., Kuhlers, D.L. (1986). Ultrasonographic evaluation of normal boar testicles. Am J Vet Res. 47, 2543-2548.

3. Clark, S.G., Schaeffer, D.J., Althouse, G.C. (2003). B-mode ultrasonographic evaluation of paired testicular diameter of mature boars in relation to average total sperm numbers. Theriogenology. 60, 1011-1023.

4. Finko, D.R. (1974). Biopsy of the testicle. Vet. Clin. North. Am. 4, 377-381.

5. Galina, C.S. (1971). An evaluation of testicular biopsy in farm animals. Vet Rec. 88, 628-631.

6. Hall, L.B., Kluge, J.P., Evans, L.E., Clark, T.L., Hill, H.T. (1984). Testicular Changes Observed in Boars Following Experimental Inoculation with Pseudorabies (Aujesky's) Virus. Can J Comp Med. 48, 303-307.

7. Kiernan, J.A. (2008). Histological staining in one or two colours. In: Histological and Histochemical Methods. Theory and Practice. 4th ed.(pp. 141-174). UK: Scion Publishing, Ltd.

8. Leme, D.P., Papa, F.O. (2010). How to Perform and Interpret Testicular Fine Needle Aspiration in Stallions. JEVS. 590-596.

9. Lopate, C., Threlfall, W.R., Rosol, T.J. (1989). Histopathologic and gross effects of testicular biopsy in the dog. Theriogenology. 32, 585-602.

10. Lunstra, D.D., Echternkamp, S.E. (1988). Repetitive testicular biopsy in the ram during pubertal development. Theriogenology. 29, 803-810.

11. Nyland, T.G., Matton, J.S. (2002). Small Animal Diagnostic Ultrasound. $2^{\text {nd }}$ ed. (pp. 259-263). Saunders.

12. Roset, J.F., Faber, N.F. (2007). Testicular biopsy. In: Current therapyin equinereproduction.(pp.205-209). Saunders Elsevier.

13. Threfall, W.R., Lopate C. (1993). Testicular biopsy. In: A.O. McKinnon, J. L. Voss (Eds.), Equine reproduction. (pp. 943-949). Philadelphia: Lea \& Fabiger. 